\title{
Polimerozko zuntz optiko dopatuen erabilera laser eta anplifikagailu gisa
}

\author{
Igor Ayesta*, Felipe Jiménez \\ Matematika Aplikatua Saila, Euskal Herriko Unibertsitatea (UPV/EHU), \\ Bilboko Industria Ingeniaritza Teknikoko Unibertsitate Eskola, 48013 Bilbo \\ Jon Arrue, Joseba Zubia \\ Komunikazioen Ingeniaritza Saila, Euskal Herriko Unibertsitatea (UPV/EHU), \\ Bilboko Ingeniaritza Goi Eskola Teknikoa, 48013 Bilbo \\ María Asunción Illarramendi \\ Fisika Aplikatua I Saila, Euskal Herriko Unibertsitatea (UPV/EHU), \\ Bilboko Ingeniaritza Goi Eskola Teknikoa, 48013 Bilbo \\ *igor.ayesta@ehu.eus
}

DOI: $10.1387 /$ ekaia.14552

Jasoa: 2015-05-31

Onartua: 2015-06-15

Laburpena: Artikulu honetan, gure eredu konputazionalaren bitartez, argi-anplifikazioaren ezaugarriak aztertu dira dopaturiko polimerozko zuntz optikoetan (PZOetan). Hain zuzen ere, zenbakizko irekiduraren eta dopantearen distribuzio erradialaren eraginaz gain, ponpaketaren denborazko pultsu-zabalera egokiena ere ikertu da. Analisi hauek guztiak maila-indize eta indize gradualeko PZOentzat egin dira. Lorturiko emaitzak energia desberdinetako argi-pultsuen bitartez longitudinalki kitzikaturiko zuntz aktiboetan oinarritzen dira.

Hitz gakoak: polimerozko zuntz optikoak, anplifikagailuak, laserrak, anplifikazioa, irabazia.

\begin{abstract}
This paper analyzes the peculiarities of light amplification in doped polymer optical fibres (POFs) by using our computational model under diverse conditions. Specifically, the influence of the numerical aperture and of the radial distribution of the dopant in the fibre, on the one hand, and the most convenient temporal width of the pump pulse, on the other hand, are investigated. Analyses are carried out for both stepindex and graded-index POFs. The results presented correspond to fibres excited longitudinally with short light pulses of several energies.
\end{abstract}

Keywords: polymer optical fibre, amplifiers, lasers, amplification, gain. 
Igor Ayesta, Jon Arrue, Felipe Jiménez, María Asunción Illarramendi, Joseba Zubia

\section{SARRERA}

Polimerozko zuntz optikoak (PZOak) oso erabilgarriak dira gaur egun eskaintzen dituzten ezaugarri interesgarriei esker, hala nola, malgutasuna, zurruntasun mekanikoa, diametro handia eta erabilera erraza. Erabilera tipikoen artean, distantzia laburretako komunikazio sareak, sentsore optikoak eta zuntz optiko bidezko iluminazioa ditugu [1]. Horietaz gain, dopante organikoekin edo erdieroale organikoekin dopatuz gero, efizientzia altuko laser, anplifikagailu eta kommutadore erabat optikoak garatu daitezke [2][6]. Adibidez, PZOetan oinarrituriko laserraren aplikazio posibleetako bat 1 irudian ikus daiteke. Laser diodo batek igorritako argia modu bakarreko zuntz baten bukaeran fokatu nahi izanez gero, argiaren frakzio txiki bat fokatzea baino ez genuke lortuko zuntzaren nukleoan. Lente zilindrikoen laguntzarekin ere, argiaren parterik handiena galduko litzateke akoplamendu prozesuan. PZOetan oinarrituriko laserrek arazo horri aurre egin diezaiokete. Izan ere, 1 irudiaren kasuan, laserraren eta PZO sistemaren zenbakizko irekidurek bat egiten badute, bi parteen arteko akoplamendua garbia izango da, eta akoplamendu-galerak era nabarmenean saihestu dira horrela. Dena den, abantaila hori soilik ez da izaten erabakigarria, zenbait erdieroalezko laserrek ere badutelako akoplamendu-efizientzia altua, baina laser horiek espektro-zabalera txikiko igorpena ematen dute, eta PZOzko laserrek, aldiz, espektro-zabalera handiko igorpena eman dezakete. Are gehiago, espektro zabala eta akoplatutako potentzia altua ez ezik, oso interferentzia-patroi ahula ere lor daiteke igorpenean («speckle-free» ingelesez) PZOzko laserrekin. Hiru ezaugarri horiek oso egokiak dira espektroskopian, koherentzia handiko tomografian, zenbait sentsore optikotan, eta giroskopoetan, besteak beste. Era berean, PZOzko anplifikadoreek badituzte beren aparteko abantailak ere, hala nola erabiltzeko erraztasuna eta, dopante organikoekin dopatuz gero, lehen azaldu ditugunak.


1. irudia. (Goian) Laser-diodoaren eta zuntzaren arteko akoplamendua. (Behean) PZOzko laserraren eta zuntzaren arteko akoplamendua.

Izan ere, aipaturiko dopante organikoek xurgapen eta igorpen gurutzesekzio handiak dituzte. Adibidez, PZOetan erabil daitekeen Errodamina B 
dopantearen kasuan, dituen gurutze-sekzioak 10.000 aldiz handiagoak dira Erbioak beirazko zuntzetan dituenak baino. Gurutze-sekzio horiek, modu laburrean esanda, argiaren eta dopantearen arteko interakzioaren probabilitatea adierazten dute. Beraz, zenbat eta altuagoak izan, orduan eta eraginkorragoak izango dira dopante horiekin eraiki daitezkeen gailu optikoak. Horretaz gain, zuntz optikoen izaera morfologikoa dela eta, nukleoan argi-dentsitate altua lortzen da. Ondorioz, zuntz optikoak emisio estimulatuak errazten ditu, eta efizientzia hobetu egiten da. Efizientzia edo irabazi optiko totala kalkulatzeko orduan, zuntza bera ez ezik, zuntza kitzikatzeko erabilitako laser-pultsua ere - hau da, ponpaketa-pultsua - kontuan hartu behar da. Oro har, pultsu honen ezaugarriak (uhin-luzera, potentzia eta iraupena) egokiak direnean, PZOetan irabazi altuak lor daitezke, bai maila-indizekoetan (MI) bai eta indize gradualekoetan (IG). Hala ere, zuntz optiko mota bakoitzean portaera bereziak agertzen dira, artikuluan zehar azpimarratuko den bezala. Ez dezagun ahaztu dopaturiko MI zuntzetan dopantearen kontzentrazioa distantzia erradialarekiko konstante mantentzen den bitartean, GI zuntzen kasuan hazi egiten dela zuntzaren simetria ardatzerantz hurbiltzean. Beraz, kontzentrazioa maximoa da argiaren intentsitatea maximoa den leku berean. Horrek argiaren eta dopantearen arteko interakzioa errazten du.

Fenomenoak hobeto ulertu ahal izateko, artikulu honetan PZOzko laserren eta anplifikagailuen analisi konputazionala egin da, aipatutako bi zuntz motak (MI eta IG) aztertuz. Alde batetik, PZOzko laserren maldaefizientzia eta ataria konputazionalki aztertu dira, zenbakizko irekiduraren (NA) eta ponpaketa ezaugarrien menpe. Beste aldetik, anplifikagailuen seinale-irabazia zenbakizko irekiduraren menpe aztertu da. Horretarako, dopaturiko PZOetan zehar hedatzen den argiaren ezaugarri tenporal eta espektralak kalkulatzeko balio duen gure aurreko eredu matematiko baten oinarriturik, eredua egokitu egin dugu bai dopantearen eta bai argi-potentziaren distribuzio ez-uniformeak kontuan hartzeko. Analisi konputazional horiek oso erabilgarriak izan daitezke PZOzko laserren eta anplifikagailuen diseinatze etapan.

Artikulua honela antolatu da: 2. atalean dopaturiko MI eta IG PZOen oinarri teorikoak, eredu matematikoa eta sistema eredua azaldu dira. 3. atalean lorturiko emaitza konputazionalak erakutsi eta eztabaidatu dira. Azkenik, 4. atalean ondorioak laburbildu dira.

\section{DOPATURIKO PZO-AK}

\subsection{Oinarri teorikoak}

Hurrengo lerroetan zuntzaren nukleoan txertaturiko dopanteen portaera deskribatuko da beren trantsizio energetikoen ikuspuntutik. 2. irudian ikus 
Igor Ayesta, Jon Arrue, Felipe Jiménez, María Asunción Illarramendi, Joseba Zubia

daitekeen bezala, dopante organiko eta polimero konjokatuekin dopaturiko PZOen energia-diagrama sinplifikagarria da, bi energia-maila dituen sistema bat izango balitz bezala har daitekeelako: $S_{2}$ eta $S_{1}$. Fotoi-igorpenetan trantsizioak $S_{2}$-ren beheko azpimailatik $S_{1}$-era gertatzen dira, eta fotoi-xurgapenetan alderantziz; hau da, $S_{1}$-en beheko azpi-mailatik $S_{2}$-ra. Ondorioz, dopaturiko zuntzen ezaugarri optikoak bi energia-mailen arteko denboraren menpeko tasa-ekuazioen bitartez aztertzen dira normalean [7]. Zehatzagoak izateko, determinatu beharreko funtzio ezezagunak honako hauek dira: $P(t, z, \lambda)$ (denbora, posizioa eta uhin-luzeraren menpeko argi-potentzia) eta $N_{2}(t, z)$ (denbora eta posizioaren menpeko populazio elektronikoa, kitzikaturiko egoeran). Aldagai espazial independente bakarra zuntzaren simetria ardatzean neurtutako posizioa da (z), bai MI zuntzetan bai IG zuntzetan. Azken horiek konplexuxeagoak dira, argiaren eta dopantearen arteko interakzioaren probabilitatea handitu egiten delako, bai errefrakzio-indizea eta bai argi-potentziaren dentsitatea ere handiak direlako eskualde berean (zuntzaren simetria ardatzean). Efektu hau gure ekuazioetan kontuan hartzeko, $\gamma$ gainjarpenfaktorea erabili dugu, hari 1 baino handiagoko balioa emanik IG zuntzetan eta 1 MI zuntzetan [7]. Posizioaz gain, badaude beste bi aldagai independente: denbora $(t)$ eta uhin-luzera $(\lambda)$. Argi-potentziaren analisi espektrala egitea posiblea izango da potentziak uhin-luzerarekiko duen menpekotasuna kontuan hartzen bada. Menpekotasun hori sartzeko, dopantearen xurgapen eta igorpen gurutze-sekzioak erabili ditugu, hots $\sigma_{a b s}(\lambda)$ eta $\sigma_{e m i}(\lambda)$. Horrek, $N_{2}=N_{2}(t, z)$ aintzat hartzea ahalbidetzen digu. Hori horrela izanik, igorpen uhin-luzera bakoitzean sortzen den potentzia $\sigma_{\text {emi }}(\lambda)$-rekiko haztaturik dago, alegia, sortutako argi-potentziaren espektroa $\sigma_{\text {emi }}(\lambda)$-ren menpean egongo da.

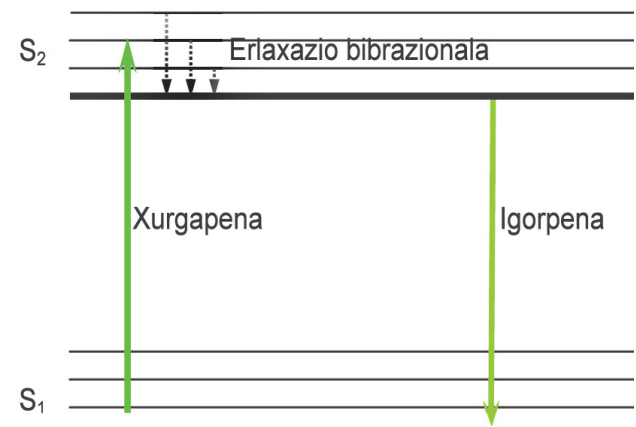

2. irudia. Dopante organiko eta polimero konjokatuen xurgapen eta igorpen prozesuen erantzuleak diren energia mailak.

Bolumen unitateko molekula dopatzaileen kontzentrazio totala $(N)$ denborarekiko independentea denez, posible izango da $N_{1}(t, z)=N-N_{2}(t, z)$ 
erlazioa kontuan hartzea. Erlazio honetan, $N_{1}$ eta $N_{2}$ oinarrizko egoerako eta kitzikaturiko egoerako populazio elektronikoak dira, hurrenez hurren.

Honakoak dira behar diren deribatu partzialetako ekuazio nagusiak argi-potentzia zuntzaren zeharreko edozein puntutan $z$, edozein momentu$\tan t$, eta edozein uhin-luzeratan $\lambda$ ebaluatu ahal izateko [8]:

$$
\begin{aligned}
& \frac{\partial N_{2}}{\partial t}=\frac{-N_{2}}{\tau}-\frac{\sigma_{e m i}\left(\lambda_{k}\right) N_{2}}{h\left(c / \lambda_{k}\right) A_{\text {core }}} P \gamma+\frac{\sigma_{a b s}\left(\lambda_{p}\right) N_{1}}{h\left(c / \lambda_{p}\right) A_{\text {core }}} P \gamma+\frac{\sigma_{a b s}\left(\lambda_{k}\right) N_{1}}{h\left(c / \lambda_{k}\right) A_{\text {core }}} P \gamma \\
& \frac{\partial P}{\partial z}=\sigma_{e m i}\left(\lambda_{k}\right) N_{2} P \gamma-\sigma_{a b s}\left(\lambda_{k}\right) N_{1} P \gamma-\frac{1}{v_{z}} \frac{\partial P}{\partial t}+\frac{N_{2}}{\tau} h \frac{c}{\lambda_{k}} \sigma_{s p}^{e}\left(\lambda_{k}\right) \beta A_{\text {core }}
\end{aligned}
$$

$P_{p}$ ponpaketa-potentzia da; $v_{z}$, berriz, argiaren abiadura medioan, nukleoko errefrakzio indizearen menpe dagoena; $c, h, \tau$ eta $A_{\text {core }}$, hurrenez hurren, argiaren abiadura, Planck-en konstantea, fluoreszentzia-erdibizitza, eta nukleoaren gurutze-sekzioa dira. $\gamma$-ren balio zehatza 1 eta 2 artekoa izaten da ohiko argi-distribuzio erradiala duten IG PZOetan [8]. (1) ekuazioko eskuin aldeko lehenengo eta bigarren terminoek berezko igorpena eta igorpen estimulatua adierazten dute. Hirugarren eta laugarren terminoek, ordea, ponpaketaren ondoriozko kitzikapena eta birxurgapena itxuratzen dute. (2) ekuazioko eskuin aldeko terminoek igorpen estimulatua, materialaren xurgapena, zuntzaren zeharreko argiaren propagazioa eta berezko igorpena adierazten dute, hurrenez hurren.

Eredua ponpaketa-potentziaren distribuzioarekin eta mugalde-baldintzekin osotu behar da. Luzetarako kitzikapenaren kasuan, zuntzaren simetria-ardatzaren zeharreko noranzkoan $\left(\lambda_{P}\right.$ uhin-luzeran) argi-potentziaren distribuzioa deskribatzen duen ekuazioa hurrengoa da:

$$
\frac{\partial P_{p}}{\partial z}=-\sigma_{a b s}\left(\lambda_{p}\right) N_{1} P_{p} \gamma-\frac{1}{v_{z}} \frac{\partial P_{p}}{\partial t}
$$

Artikuluan zehar, PZOzko laser eta anplifikagailuen igorpen-ezaugarrietan zuntzaren zenbakizko irekidurak duen eragina erakutsiko da, batez ere PZOzko laserretan. Izan ere, laserretan erabilgarria da berezko igorpen anplifikatua (ingelesez Amplified Spontaneous Emission, edo ASE), ez ordea seinale anplifikagailuetan. Zenbakizko irekiduraren eragina $\beta$ parametroaren bitartez sartu da ekuazioetan. Jakina den bezala, ASE-atariaren gainetik zuntzaren irteerako energiak ponpaketa energiarekiko menpekotasun lineala du. Haren maldari malda-efizientzia esaten zaio, eta ASE-ataria ardatz horizontalarekiko ebakidura gisa definitzen da.

(1)-(3) ekuazioak baliozkoak dira maila-indize eta indize gradualeko zuntzentzat, baldin eta beharrezko aldaketak egiten badira $\beta$-ren eta $\gamma$-ren balioetan [7]. Alde batetik, $P$ (edo $P_{p}$ ), $N_{1}$-ekin (edo $N_{2}$-rekin) biderka- 
Igor Ayesta, Jon Arrue, Felipe Jiménez, María Asunción Illarramendi, Joseba Zubia

tuta agertzen den termino bakoitzean $\gamma$ gainjarpen-faktorea sartu behar da: $\gamma=1$ MI zuntzetan eta $\gamma>1$ IG zuntzetan. Arrazoia sinplea da. IG zuntzak egiteko erabilitako ohiko fabrikazio tekniken ondorioz, handiagoak dira eskualde berean bai dopantearen kontzentrazio molekularra eta baita fotoien kontzentrazioa ere, biak hazten baitira zuntzaren simetria-ardatzerantz hurbiltzean. Ondorioz, elkarri eragiteko probabilitatea ere handiagoa da. Aitzitik, maila-indizeko zuntzen kasuan, dopante-molekulen kontzentrazio totala $(N)$ uniformeki banaturik dago distantzia erradialarekiko, beraz, $\gamma=1$.

1. taula. Maila-indize (MI) eta indize gradualeko (IG) PZOen $\beta$ eta $\gamma$ parametroen espresio eta balio ohikoak.

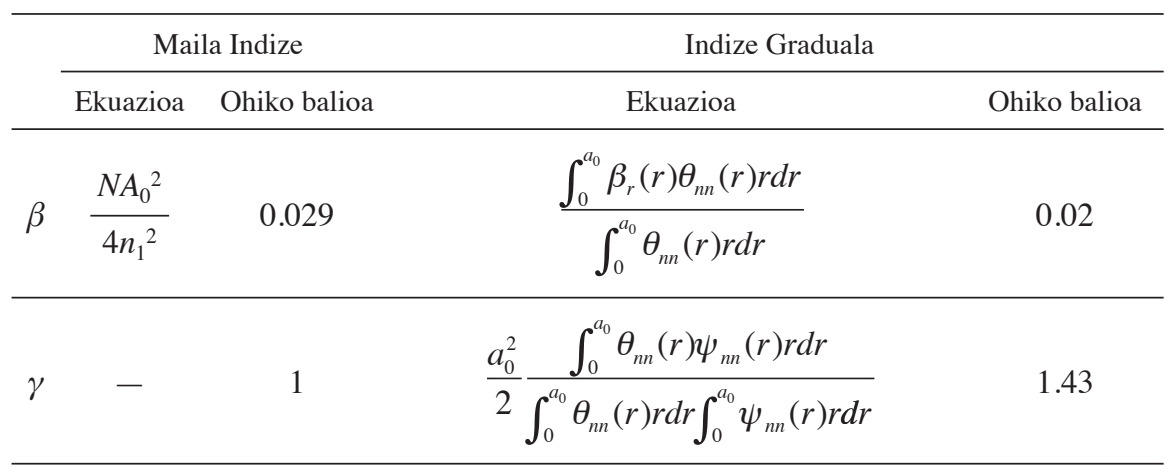

Beste alde batetik, IG zuntzen kasuan, beharrezkoa da $\beta$-ren batez besteko balioa kalkulatzea, zenbakizko irekidura distantzia erradialarekin ( $r$-rekin) aldatzen delako. Maila-indizeko zuntzaren kasuan, ordea, $\beta$-ren batez besteko balioa zuntzaren gurutze-sekzioarena $\left(\beta_{0}\right)$ da. 1. taulan laburbildurik ikus daitezke $\beta$ eta $\gamma$ parametroen balio ohikoak zuntz mota bakoitzarentzat.

\subsection{Sistema eredua}

Aipaturiko ekuazio diferentzialak hurrengo hasierako baldintzekin askatu dira: $P$ eta $N_{2} 0$ balioarekin hasieratzen dira $t=0$ unean, ez delako existitzen kitzikaturiko molekularik $\left(N_{2}\right)$, ezta argi-potentziarik $(P)$ ere.

Mugalde-baldintzei dagokienez, ponpaketa-potentziaren pultsua honela deskriba daiteke:

$$
P_{p}\left(z_{i}, t, \lambda_{p}\right)=\frac{E_{p}}{\sigma \sqrt{2 \pi}} e^{\frac{-\left(t-t_{\text {peak }}\right)^{2}}{2 \sigma^{2}}}
$$


Formulako $\sigma$-k zabalera efektiboa (FWHM/2.35) adierazten du, $E_{P}$ sarrerako pultsuaren energia da eta $t_{\text {peak }} 5 \sigma$ neurrikotzat hartu da potentzia baztergarria izan dadin $t=0$ unean. Aipaturiko kitzikapen pultsuaz gain, PZOzko anplifikagailuetan bigarren Gaussen pultsu bat gehitzen da seinale moduan, $z=0$ posizioan eta $\lambda_{s}$ uhin-luzeran zentraturik.

Ekuazioak ebazteko erabilitako metodo numerikoa diferentzia finituetan oinarritzen da. Zehatzagoak izateko, $t$, $z$ eta $\lambda$ aldagaien balio diskretuak erabiltzen dituen diferentzia finituko ad hoc algoritmoa garatu da [9]. Aldagai espazial eta tenporalaren diskretizazioa uniformea izan da, hau da, $\delta t$ eta $\delta z$ urrats-tamaina finitu konstanteekin. Adibidez, $\delta t$ urrats-tamaina tenporala $0.5 \mathrm{~ns}$-koa izan da, $\delta z$ urrats-tamaina espaziala $0.24 \mathrm{~mm}$-koa izan da eta uhin-luzera tarteen kopurua 200 izan da gutxienez. PZOzko anplifikagailuen ezaugarrien modelizazioaren kasuan, sarrerako seinalea kokatzen den espektroaren tartea puntu kopuru minimo batekin modelatu da (adibidez 10 puntu), eta seinalearen espektroan finagoa den diskretizazioa erabili da.

Deskribaturiko eskema numerikoa inplementatzeko orduan, bi indizeko $N_{2}(i, j)$ matrizea erabili da $N_{2}$-ren balio diskretuak biltegiratzeko. Lehenengo indizeak denbora diskretua zehazteko balio du, $t_{i}=(i-1) \delta t$-ren bitartez. Bigarrenak $z$ posizioa zehazteko balio du, $z_{j}=(j-1) \delta z$-ren bitartez. Modu berean, 3 dimentsioko $P(i, j, k)$ matrizea erabili da argi-potentziaren distribuzioaren balio diskretuak biltegiratzeko. Hirugarren indizeak $(k)$ aipaturiko diskretizazio ez-uniformearen bitartez $\lambda$ uhin-luzera determinatzen du, eta $i$ eta $j$ indizeak aurrekoen berdinak dira. Azkenik, uhin-luzera diskretu bakoitzarentzat diferentzia finituen bitartez estimatu da ekuazioko termino bakoitza. Zehaztasun handiagoa lortzeko, diferentzia finituak, ahal den heinean, zentraturik egon dira. $N_{2}(i, j)$ eta $P(i, j, k)$ matrizeak zutabez zutabe osatu dira.

Konputazio-kostuak ez dira oso handiak izan. Beraz, Matlab ${ }^{\circledR}$ bezalako maila altuko programazio-lengoaia aukeratu da, $\mathrm{C}++$ bezalako lengoaia bizkorragoak baztertuz. Adibide moduan, Matlab ${ }^{\circledR}$ softwarearen 7.5 bertsioa Dell Precision ${ }^{\mathrm{TM}}$ M6400 ordenagailu eramangarrian exekutatuz gero (Intel ${ }^{\circledR}$ Core $^{\mathrm{TM}} 2$ Duo Quad Core prozesagailua eta 4 GB DDR3 SDRAM $1.066 \mathrm{MHz}$ ), ohiko simulazio batek minutu bat inguru baino ez du irauten ezarritako hasierako baldintzetarako.

\section{EMAITZA KONPUTAZIONALAK}

Maila-indizeko eta indize gradualeko PZO aktiboen hedapeneko ezaugarrien analisia eta konparaketa egin dira. Alde batetik, zenbakizko irekidura kontuan hartu da, eta, bestetik, bai zuntzen nukleoko argi-potentziaren dentsitatearen distribuzioa eta bai dopante-kontzentrazioaren distribuzioa hartu dira aintzat. Zehazki, sarrera-seinalerik gabe (PZOzko laserretan) eta 
Igor Ayesta, Jon Arrue, Felipe Jiménez, María Asunción Illarramendi, Joseba Zubia

sarrera-seinalearekin (PZOzko anplifikagailuetan) lortutako emaitzak erakusten dira.

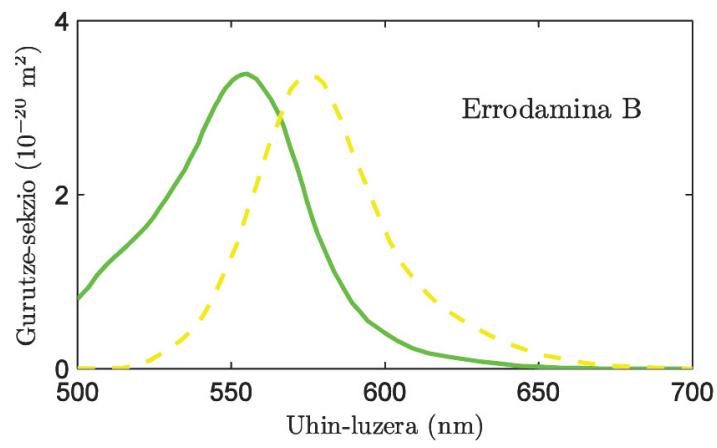

3. irudia. Errodamina B-ren xurgapen- (lerro solidoa) eta igorpen- (lerro marratua) espektroak PMMA materialean.

Emaitzak aurreko atalean erakutsitako ereduarekin kalkulatzeko, xurgapeneko eta igorpeneko gurutze-sekzioak ezagutu behar izan ditugu. Errodamina B molekularekin dopaturiko PZOen kasuan, erabilitako datuak 3. irudian ikus daitezke [10], [11]. Horrez gain, lortutako emaitzak egoera erreal bateko emaitzen baliokideak izan daitezen, esperimentalki neurtutako parametro berdinak erabiliz egin dira simulazioak [4], [12] (ikus 2. taula).

2. taula. Errodamina B-rekin dopaturiko MI eta IG PZOzko laser eta anplifikagailuak simulatzeko erabilitako parametroak.

\begin{tabular}{lcc}
\hline \multicolumn{1}{c}{ Parametroa } & Notazioa & Balioa \\
\hline Seinalearen potentzia (egotekotan) & $P_{s}$ & $1 \mathrm{~W}$ \\
Seinalearen uhin-luzera & $\lambda_{s}$ & $591 \mathrm{~nm}$ \\
Seinalearen zabalera tenporala & $\mathrm{FWHM}$ & $3.5 \mathrm{~ns}$ \\
Ponpaketaren potentzia & $P_{p}$ & $5,11 \mathrm{~kW}$ \\
Ponpaketaren uhin-luzera & $\lambda_{\mathrm{p}}$ & $532 \mathrm{~nm}$ \\
Ponpaketaren zabalera tenporala & $\mathrm{FWHM}$ & $6 \mathrm{~ns}$ \\
Seinalearen atenuazioa & $\alpha\left(\lambda_{s}\right)=\alpha_{s}$ & $8.50 \mathrm{~dB} / \mathrm{m}$ \\
Ponpaketaren atenuazioa & $\alpha\left(\lambda_{p}\right)=\alpha_{p}$ & $8.13 \mathrm{~dB} / \mathrm{m}$ \\
Zuntzaren luzera & $L$ & $1 \mathrm{~m}$ \\
Nukleoaren erradioa & $a_{0}$ & $0.25 \mathrm{~mm}$ \\
Xurgapeneko gurutze-sekzioa $\left(\lambda_{p}\right)$ & $\sigma_{a b s}\left(\lambda_{p}\right)$ & $2.2 \cdot 10^{-20} \mathrm{~m}^{2}$ \\
Igorpeneko gurutze-sekzioa $\left(\lambda_{s}\right)$ & $\sigma_{e m i}\left(\lambda_{s}\right)$ & $2.3 \cdot 10^{-20} \mathrm{~m}^{2}$ \\
Fluoreszentzia-erdibizitza & $\tau$ & $2.85 \mathrm{~ns}$ \\
Dopantearen kontzentrazioa & - & $0.13 \mathrm{ppm}$ \\
\hline
\end{tabular}




\subsection{Malda-efizientzia eta ataria MI eta IGko PZOzko laserretan}

Hasteko, parametro desberdinen menpeko PZOen malda-efizientzia eta ASE-atariaren eboluzioak erakutsiko ditugu, MI eta IG zuntzetan. Lehenik eta behin, ASE igorpeneko ezaugarrietan simetria ardatzeko zenbakizko irekiduraren $\left(N A_{0}\right.$-ren) eragina zein den aztertzen hasiko gara.
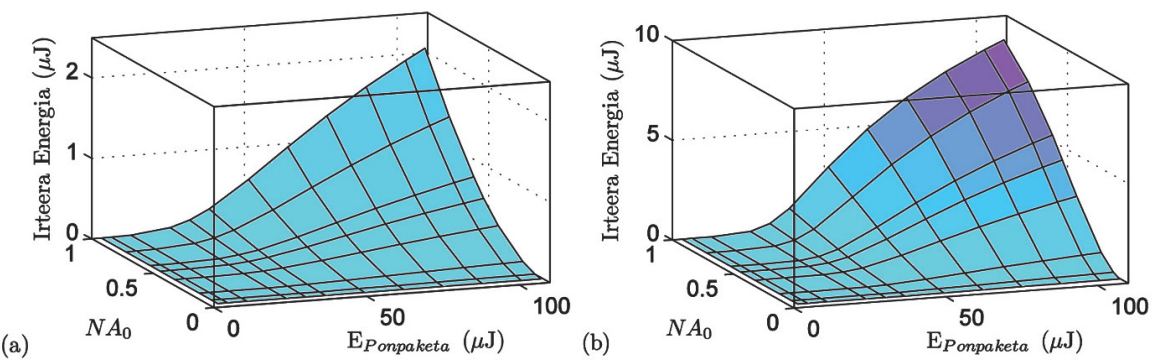

4. irudia. Zuntza energia desberdinekin kitzikatzean $581 \mathrm{~nm}$-ko irteerako energiak duen eboluzioa, zenbakizko irekiduraren balio desberdinetarako. (a) MI PZOetan eta (b) IG PZOetan, $\gamma=1,43$ denean eta 2. taulako parametroekin.

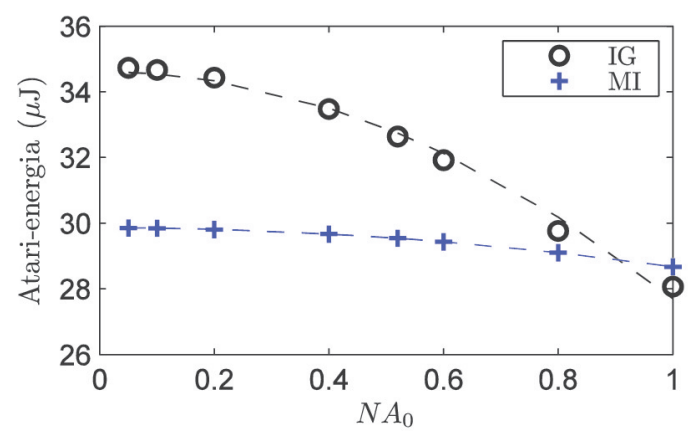

5. irudia. ASE-ataria $581 \mathrm{~nm}$-tan zuntzaren ardatzeko zenbakizko irekiduraren menpe. MI (zirkulu-markatzaileak) eta IG (gurutze-markatzaileak) PZOetan, $\gamma=1,43$ denean, 2. taulako parametroekin. Lerro marratuek Thr $=c_{1} \cdot N A_{0}{ }^{2}+c_{2}$ adierazpena betetzen dute, MI PZOen kasuan $c_{1}=-1,18$ eta $c_{2}=29,8$ eta IG PZOen kasuan $c_{1}=6,91$ eta $c_{2}=34,6$.

4. irudiak zuntzaren zenbakizko irekidurak eta ponpaketa-energiak irteerako energian (581 nm-tan) duten eragina adierazten du. Kualitatiboki, MI eta IG PZOen eboluzioa berdina da (ikus 4(a) irudia eta 4(b) irudia, hurrenez hurren). Ponpaketa-energia baxua denean, igorritakoa gehienbat igorpen espontaneoaren ondorioa da. Hori dela eta, irteerako energia malda txikiarekin hazten da. Atariaren gainetik, ordea, populazio-inbertsioa gerta- 
Igor Ayesta, Jon Arrue, Felipe Jiménez, María Asunción Illarramendi, Joseba Zubia

tzen denez, espontaneoki igorritako fotoiak anplifikatu egiten dira zuntzaren zeharreko iraganaldi bakarrean. Ponpaketa-energia oso altuekin, nabariak dira saturazio efektuak, kurben maldak murrizten dituztelarik. Atariaren gainetik, irteerako energia altuagoak lortzen dira $N A_{0}$-ren balio altuetarako, espero bezala. Izan ere, $N A_{0}$-ren balio altuekin fotoi gehiago hedatuko dira zuntzean zehar, eta haiek igorpen estimulatu gehiago sortuko dituzte. Hori horrela izanik, ez da arraroa zuntzaren irteeran energia gehiago izatea. Gainera, aipa dezagun $N A_{0}$-ri balio berdina emanez gero, IG zuntzen irteerako energia lau aldiz handiagoa dela MI zuntzekin lortutakoa baino. Horren arabera, IG PZOzko laserretan, irteerako energian gainjarpen-faktorearen $(\gamma$ ren) eragina are handiagoa da, alegia, MI PZOetan NA-ren (edo $\beta$-ren) batez besteko balio handiago bat izatearen eragina baino.

Atari energiak eta malda-efizientziak lortzeko, 4. irudiko kurba bakoitzari hurbilketa-kurba zuzen bat doitu diogu [13]. 5. irudian ikusten den bezala, atarira heltzeko beharrezko energia gutxiagotu egiten da $N A_{0}$ handiagoa denean. Ausazko laserretan ere eboluzio bera gertatzen da [14]. Gainera, $N A_{0}$-ren menpeko atari-energiaren eboluzioa funtzio koadratiko batekin doitu daitekeela ere erakusten du, bai MI eta baita IG PZOetan ere. (1) eta (2) ekuazioetatik abiatuta, kalkulu sinple eta hurbilduak egin ditugu, dopante molekulen populazio-inbertsioa $\left(N_{1} \approx N_{2}\right)$ gerta dadin beharrezko ponpaketa-atariaren espresio analitikoa lortzeko asmoz [9]:

$$
P_{p}^{t h}=\frac{h\left(c / \lambda_{p}\right) A_{\text {core }}}{\tau \lambda \sigma_{a b s}\left(\lambda_{p}\right)}(1-\beta) \propto\left(1-N A_{0}^{2}\right)
$$

Ikus daitekeen moduan, ekuazio honek 5. irudian ikusitako eboluzio kualitatiboa egiaztatzen du.

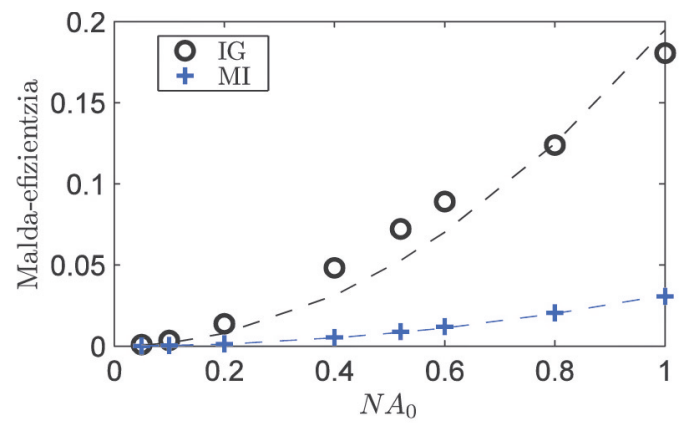

6. irudia. Malda-efizientzia $(\eta) 581 \mathrm{~nm}$-an zuntzaren ardatzeko zenbakizko irekiduraren menpe, MI PZOetan (zirkulu-markatzaileak) eta IG PZOe$\tan$ (gurutze-markatzaileak) $\gamma=1,43$ denean, 2. taulako parametroekin. Lerro marratuek $n=c_{1} N A_{0}^{2}$ adierazpena betetzen dute, MI PZOen kasuan $c_{1}=0,031$ eta IG PZOen kasuan $c_{1}=0,2$ direlarik, hurrenez hurren, kasu bakoitzean . 
Malda-efizientziei dagokienez, haiek $N A_{0}$ balio altuekin askoz ere altuagoak izan daitezke, espero bezala (ikus 6. irudia). Marra-lerroek, gainera, erakusten dute zenbakizko irekiduraren menpeko malda-efizientziaren eboluzioa funtzio koadratiko batekin doitu daitekeela.

Ponpaketa-atariaren kasuan egindakoaren antzera, (2) eta (3) ekuazioetatik beste kalkulu analitiko bat egin da malda-efizientziaren espresio analitikoa lortzeko asmoz [9]:

$$
\eta=\frac{N_{2}}{N_{1}} \frac{\left(h \cdot c / \lambda_{k}\right) A_{c o r e}}{\tau \sigma_{a b s}\left(\lambda_{p}\right) P_{p} \gamma} \beta \propto N A_{0}^{2}
$$

Horrek malda-efizientziaren eboluzio koadratikoa azaltzen du.

Azkenik, 6. irudiak erakusten duen moduan, GI PZOetan (zirkulu-markatzaileak) lorturiko balio maximoak ez dira MI PZOetan (gurutze-markatzaileak) lorturikoen bezain altuak. Gainjarpen-faktorearen eragina batez besteko $N A$-rena baino handiagoa dela erakusten du horrek berriro ere.

7. irudiak ponpaketa-pultsuaren zabalera tenporalak atarian eta efizientzian duen eragina erakusten du. Zehatzagoak izateko, luzetara kitzikaturiko ohiko MI PZOaren denborazko ponpaketa-zabalerarekiko $\left(\sigma_{t, p u m p}\right.$-rekiko) eboluzioa erakusten du. Hurrengo kalkuluetarako erabilitako parametroak ondorengoak dira: kontsideraturiko dopantearen kontzentrazioa $1 \mathrm{ppm}$ da, nukleoko erradioa $0,5 \mathrm{~mm}$ da eta ardatzeko errefrakzio indizea $n_{1}=1,492 \mathrm{da}$. Honez gain, MI PZOa, $N A_{0}=0,51$, $\gamma=1$ eta zuntzaren luzera $L=17 \mathrm{~cm}$ dela kontsideratu da.
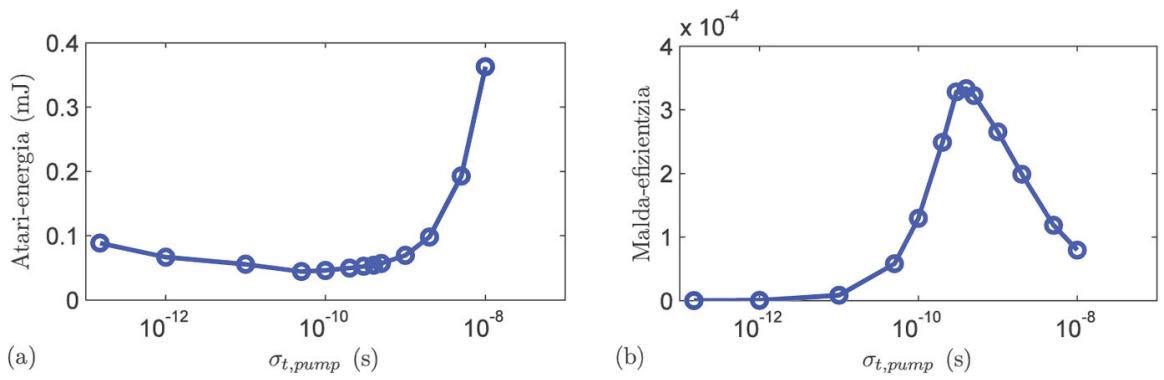

7. irudia. (a) Atari-energia eta (b) malda-efizientzia, $\sigma_{t, p u m p}$ parametroaren menpe.

7(a) irudian ASE-ataria minimizatzen duen ponpaketaren pultsu-zabalera tenporal optimo bat dagoela ikus daiteke, $0,1 \mathrm{~ns}$ inguruan hain zuzen ere. Pultsu zabalagoentzako, atariak bizkor egiten du gora. Pultsu-zaba- 
Igor Ayesta, Jon Arrue, Felipe Jiménez, María Asunción Illarramendi, Joseba Zubia

lera optimoa fluoreszentzia-erdibizitza baino txikiagoa da. Antzekoa edo handiagoa denean ( $\tau=2,85$ ns Errodamina B-ren kasuan), igorpen espontaneoek ponpaketa-pultsuaren hasierako partearen bidez lorturiko populazio-inbertsioa desegiteko joera daukate. Askoz txikiagoa izatea ere txarra da, kasu horretan energia zuntzaren tarte oso laburrean soilik mantentzen delako altu, pultsua oso bizkor erortzen baita denboran. Honen ondorioz, ASE-ataria minimizatzen duen ponpaketaren pultsu-zabalera tenporal optimoa 10 ps eta $0,5 \mathrm{~ns}$ artean dagoela ikus dezakegu. 7(b) irudiak igorpenaren malda-efizientzia maximizatzen duen beste zabalera optimo bat dagoela erakusten du, 0,4 ns inguruan. Malda-efizientzia altu mantentzen duen $\sigma_{t, \text { pump }}$ balio tartea bat ere badagoela ikus daiteke, $150 \mathrm{ps}$ eta $2.000 \mathrm{ps}$ artean, hain zuzen ere. Hori horrela izanik, $\sigma_{t, p u m p} \cong 1 / 10 \tau$ aukera ona da, balio horren inguruan bai ataria eta baita malda-efizientzia ere nahiko onak direlako.

\subsection{MI eta IG PZOzko anplifikagailuen seinale-irabazia}

Hurrengo lerroetan zehar, zenbakizko irekidurak PZOzko anplifikagailuen irabazian duen eragina aztertuko da. Anplifikagailu optikoen seinaleirabaziaren definizioan, ASE igorpenari dagokion potentziaren partea kenduta egiten da, honako modu honetan:

$$
G(\lambda)(d B)=10 \log _{10} \frac{P_{o u t}(\lambda)-P_{A S E}(\lambda)}{P_{s, i n}(\lambda)}
$$

Formula honetan, $P_{s, i n}(\lambda)$ sarrerako seinalearen potentzia da, $\lambda$ uhin-luzeran zentratua.
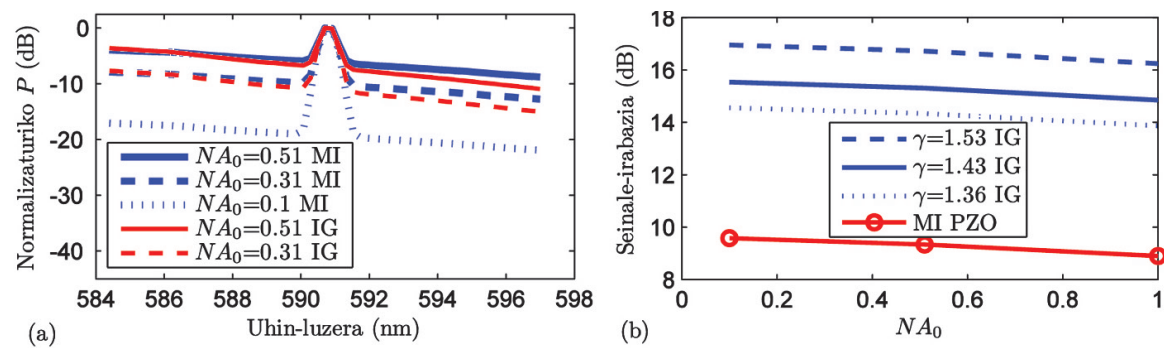

8. irudia. (a) Normalizaturiko potentzia espektralaren distribuzioa zenbakizko irekiduraren balio desberdinetarako, MI eta IG PZOetan. (b) Seinale-irabazia $N A_{0^{-}}$ ren menpe, MI eta IG PZOetan, 2. taulako parametroekin.

Lortutako emaitzak egoera erreal bati egokitzeko, PZOzko anplifikagailuekin esperimentalki erabilitako parametro berdinak erabiliz egin di- 
tugu simulazioak [11],[15] (ikus 2. taula). 8(a) irudian ikus daitekeen bezala, ASE igorpenari dagokion irteerako potentzia handiagotu egiten da zenbakizko irekidura handiagotzen den heinean, bai MI PZOen kasuan eta baita IG PZOen kasuan ere $(\gamma=1,43)$. Portaera honek ongi adierazten digu ardatzeko zenbakizko irekiduraren $N A_{0}$ handiagotzeak seinale-irabazian ondorio kaltegarriak izateko joera duela. Beste aldetik, 8(b) irudiak, espero genuen bezala, IG zuntzetan $\gamma$-ren balioa handituz gero, seinale-irabazia hobe daitekeela erakusten du, espero genuen bezala. Zehazki, $\gamma$-ren ohiko balioen tartea kontuan harturik, hots, 1,36-1,53 [11],[16],[17], seinale-irabazian $2 \mathrm{~dB}$ inguruko desberdintasunak nabari daitezke $N A_{0}$-ren edozein baliotarako. Seinale-irabazian, $\gamma$ parametroaren eragina nabaria den arren, hiru kurbek antzeko maldak dituzte. Beraz, ez dago $N A_{0}$-ren menpekotasunik $\gamma$ parametroaren eraginean. Bi motatako zuntzen seinale-irabaziak konparatuz gero, $N A_{0}$-ren balio berdinerako, IG PZOen kasuan lortzen den seinale-irabazia MI PZOen kasuan lortutakoa baino handiagoa dela ohar gaitezke. Ondorioa hurrengoa da: PZOen irabazian lortutako hobekuntzan, $\gamma$ parametroak eragin handiagoa du batez besteko zenbakizko irekidurak baino. Ohartu, gainera, zenbakizko irekiduraren eragina askoz ere nabariagoa dela PZOzko laserretan PZOzko anplifikagailuetan baino. Izan ere, ASE igorpena laserretan erabilgarria da, baina ez seinale-anplifikagailuetan.

\section{ONDORIOAK}

Artikulu honetan era konputazionalean aztertu ditugu dopaturiko MI eta IG PZOen igorpenaren ezaugarriak. Horretarako, guk diseinaturiko ad hoc algoritmo numerikoak erabili ditugu. Lortu ditugun emaitza nagusiak modu honetan laburbil daitezke: (i) Zenbakizko irekidura handitzeak atari-potentzia gutxiagotzen du eta malda-efizientzia handiagotu, bai MI PZOetan eta bai IG PZOetan. Horrez gain, laser-ataria minimizatzen duen ponpaketa-pultsuaren zabalera tenporal optimo bat dagoela ikusi dugu, eta, baita igorpenaren malda-efizientzia maximizatzen duen beste zabalera optimo bat ere; (ii) PZOzko anplifikagailuei dagokienez, $\gamma$ parametroa handitzen denean seinale-irabazia hobetzen dela erakutsi dugu. Aplikazioaren arabera, IG PZOzko anplifikagailuak edo MI PZOzkoak erabil daitezke, IG PZOzkoen kasuan irabaziaren balio hobea lortzeko aukera dugularik. MI eta IG PZOzko anplifikagailuetan, seinale-irabazia ez da zenbakizko irekidurarekin asko aldatzen. Artikulu honetan zehar erakutsitako analisiak oso erabilgarriak izan daitezke PZOzko laser eta anplifikagailuen diseinurako, elementu horien funtzionamendua eta errendimendua hobetzeko aukera eskaintzen baitute. 
Igor Ayesta, Jon Arrue, Felipe Jiménez, María Asunción Illarramendi, Joseba Zubia

\section{ESKER ONAK}

Lan honetan diruz lagundu duten erakundeak: Europar Batasuna (Eskualdeen Garapenerako Europako Funtsa), Ministerio de Economía y Competitividad (TEC2012-37983-C03-01), Gobierno Vasco/Eusko Jaurlaritza (IT664-13 eta ETORTEK14/13), Iberdrola Fundazioa (FP14/25) eta UPV/EHU (UFI11/16 eta US13/09) izan dira.

\section{BIBLIOGRAFIA}

[1] ZUBIA, J. eta ARRUE, J. 2001. «Plastic optical fibers: An introduction to their technological processes and applications». Fiber Technol., 7, 101-140.

[2] MAIER, G.V., KOPYLOVA, T.N., SVETLICHNYI, V.A., PODGAETSKII, V.M., DOLOTOV, S.M., PONOMAREVA, O.V. eta MONICH, A.E. 2007. «Active polymer fibres doped with organic dyes: Generation and amplification of coherent radiation». Quantum Electron., 37, 53-59.

[3] SHEEBA, M., THOMAS, K.J., RAJESH, M., NAMPOORI, V.P.N., VALLABHAN, C.P.G. eta RADHAKRISHNAN, P. 2007. «Multimode laser emission from dye doped polymer optical fiber emission from dye doped polymer optical fiber». Appl. Opt., 46, 8089-8094.

[4] ILLARRAMENDI, M.A., ZUBIA, J., BAZZANA, L., DURANA, G., ALDABALDETREKU, G. eta SARASUA, J.R. 2009. «Spectroscopic characterization of plastic optical fibers doped with fluorine oligomers». J. Lightwave Technol., 27, 3220-3226.

[5] CLARK, J., BAZZANA, L., BRADLEY, D.D.C., CABANILLASGONZALEZ, J., LANZANI, G., LIDZEY, D.G., MORGADO, J., NOCIVELLI, A., TSOI, W.C., VIRGILI, T. eta XIA, R. 2008. «Blue polymer optical fiber amplifiers based on conjugated fluorine oligomers». $J$. Nanophoton., 2, 521-531.

[6] LIANG, H., ZHENG, Z., LI, Z., XU, J., CHEN, B., ZHAO, H. eta ZHANG, Q. 2004. «Fabrication and amplification of Rhodamine B-doped step-index polymer optical fiber». J. Appl. Polym. Sci., 93, 681-685.

[7] ARRUE, J., JIMÉNEZ, F., AYESTA. I., ILLARRAMENDI, M.A. eta ZUBIA, J. 2011. «Polymer-Optical-Fiber Lasers and Amplifiers Doped with Organic Dyes». Polymers, 3, 1162-1180.

[8] AYESTA, I., ARRUE, J., JIMÉNEZ, F., ILLARRAMENDI, M.A. eta ZUBIA, J. 2011. «Analysis of the emission features in graded-index polymer optical fiber amplifiers». Journal of Lightwave Technology, 29, 2629-2635.

[9] AYESTA, I. 2013. Polimerozko zuntz optiko aktiboen ikerkuntza, laser eta anplifikagailu gisako funtzionamendua hobetzeko. Euskal Herriko Unibertsitatea (UPV/EHU).

[10] DE LA ROSA-CRUZ, E., DIRK, C.W., RODRÍGUEZ, A. eta CASTAÑO, V.M. 2001. «Characterization of fluorescence induced by side illumination 
of Rhodamine B doped plastic optical fibers». Fiber Integr. Opt., 20, 457464.

[11] TAGAYA, A., TERAMOTO, S., YAMAMOTO, T., FUJII, K., NIHEI, E., KOIKE, Y. eta SASAKI, K. 1995. «Theoretical and experimental investigation of Rhodamine B doped polymer optical fiber amplifiers». IEEE Journal of quantum electronics, 31, 12, 2215-2220.

[12] TAGAYA, A., KOBAYASHI, T., NAKATSUKA, S., NIHEI, E., SASAKI, K. eta KOIKE, Y. 1997. «High gain and high power organic dye-doped polymer optical fiber amplifiers: absorption eta emission cross sections and gain characteristics». Jpn. J. Appl. Phys., 36, 2705-2708.

[13] AYESTA, I., ARRUE, J., JIMENEZ, F., ILLARRAMENDI, M.A. eta ZUBIA, J. 2011. «Computational analysis of the amplification features of active plastic optical fibers». Physica Status Solidi A, 208, 1845-1848.

[14] VAN SOEST, G. eta LAGENDIJK, A. 2003. « $\beta$ factor in a random laser». Phys. Rev. E, 65, 047601.

[15] TAGAYA, A., KOBAYASHI, T., NAKATSUKA, S., NIHEI, E., SASAKI, K. eta KOIKE, Y. 1997. «High gain and high power organic dye-doped polymer optical fiber amplifiers: absorption eta emission cross sections and gain characteristics». Jpn. J. Appl. Phys., 36, 2705-2708.

[16] KURIKI. K., KOBAYASHI, T., IMAI, N., TAMURA, T., KOIKE, Y. eta OKAMOTO, Y. 2000. «Organic dye-doped polymer optical fiber laser». Polym. Adv. Technol., 11, 612-616.

[17] SASAKI, K. eta KOIKE, Y. 1995. «Polymer Optical Fibre Amplifier». U.S. Patent 5,450,232. 